\title{
Wear of Flame-Sprayed Ni-Cr-B-Si Powder Coating on Journal for Seal Contact
}

\author{
Sheng-Yen Hu, Jia-Jyun Liao and Yuan Kang \\ Chung Yuan Christian University, Department of Mechanical Engineering, 32023 Chungli, Taiwan, R.O.C
}

\begin{abstract}
Flame-sprayed techniques is used in this paper to coat Ni-Cr-B-Si powder on low-carbon steel or bearing steel materials of the journal surface. The wear tester is used to explore material properties of the binding capability, surface hardness, wear and friction within each layer depth. The normal force is applied in addition to the cladding layer by not only using bearing ball but also oil seal pieces, to explore rubber material of oil seal contact journal. In experiments to explore the material and processing conditions affect the microstructure and hardness of the cladding layer, and at the same hardness, surface roughness to affect the performance of the mill run. The results showed that spraying Ni-Cr-B-Si alloy powder in mild steel sheet to melt and run, cladding layer and the substrate has a uniform distribution of fine abrasive particles and binding effect, causing the substrate surface hardness (HRC) about promotion 10 times. While, if sprayed Ni-Cr-B-Si alloy powder to steel panels bearing surface because the surface coated compact structure, can reduce the surface roughness and the coefficient of friction, and more improve the wear resistance of the cladding layer.
\end{abstract}

\section{Introduction}

Flame spray coating method is a powder or wire heated by oxyacetylene flame with a high velocity gas jet to blow semi-molten powder coating material onto the substrate. In comparison with other thermal spraying, flame spraying is simplest, minimum limitation, and good performance in accumulation, especially for self-melt alloy powders cladded on a wide range of substrate materials. Moreover, the method has the advantage of pile efficiency, low cost, layer integrity, and large thickness to compare with physical vapour deposition (PVD)

Seal ring is contacting shaft journal by spring pressure with a relative velocity, although very different hardness between both materials, however combined surface pitting and agglutination injury can be induced by hard grit abrasion, long-term effect of high temperature and friction heat, and contact stress fatigue due to shaft rotation. Surface coating with Ni-Cr alloy powder on shaft journal can promote performances of hardness, strength, durability in medium-temperature, resistance to wear and corrosion, and low friction, et cetera. Adding $\mathrm{B}$ and $\mathrm{Si}$ can lower melt point of $\mathrm{Ni}$ and $\mathrm{Cr}$ because of eutectic in order to promote bonding and eliminate voids but hardness may be reduced slightly. Hence this paper studies the tribological performance and durability of shaft journal coating Ni-Cr-B-Si alloy powder by flame spray.

Wang et al. [1] studied adding cerium oxide and $\mathrm{Cr}$ on the high-speed gas spraying Ni-Al intermetallic layer microstructure and micro indentation and erosion of nature. Ni-Al alloy powder has strong binding, high stack of thick, base substrate for use, adding cerium oxide and chromium can help reduce the Ni-Al intermetallic in the spraying process due to too hard and brittle and cause spall. In addition to adding cerium oxide and chromium also help to improve the hardness of the coating, erosion resistance and elasticity modulus, while reducing microcracks and porosity of the coating.

Simm and Freti [2] studied multiphase material, the enhanced influence relative size and content of the abrasive wear behavior. Abrasive wear test results show that, in order to strengthen the WC particles Ni-Cr-B-Si thermal spray coating alloy has good scratch wear performance, when the WC particles of the content exceeds $30 \%$, of the WC-Ni-Cr-B-Si improve abrasion coating layer scratch wear performance is not obvious. So the abrasive particles whether it will strengthen the surface of material causing deep scratches, strengthening phase particle size is an important determinant.

Fohl et al. [3] using thermal spraying coat ceramic hard phase particles $\mathrm{WC}, \mathrm{TiC}, \mathrm{Cr} 3 \mathrm{C} 2$ and $\mathrm{Ni}$ or $\mathrm{Co}$ as a bonding phase, on a steel surface. They found the hard phase helps to increase wear resistance ability, but for larger loads the wear environment, due to the brittleness and adhesion of the hard phase with insufficient strength, abrasion resistance will be lowered, but the use of an electron beam, the coating layer can be fused again and improve this problem.

The use of Taguchi orthogonal array L18 $(21 \times 37)$ planning experiments, Lin et al. [4] have selected the target atom ratio $(\mathrm{Ti} / \mathrm{Al})$, the substrate bias voltage, nitrogen pressure, the arc current, TiAl deposition time, 
TiAlN deposition time, surface condition, sputter cleaning of eight factors, to explore the use of cathodic arc plasma deposition process for coating characteristics and wear behaviour of bulk TiAlN coating on the tool steel. Qiao et al. [5] utilized arc spraying to coat $\mathrm{Fe}-\mathrm{Cr}-$ $\mathrm{Ni}$ and explore its wear characteristics of coating layer, they found that two kinds of the abrasive mechanism and material transfer mechanisms coexist.

Hiraga et al. [6] studied plasma spraying of Ni-Ti composite coating of nest (cavitation) corrosion resistant to apply this spraying technique to high temperature dielectric deposition of metal. They found that a shape memory effect of the Ni-Ti alloy layer by arc-Ti wire spraying, plasma spraying and plasma Ni-TiCodeposition (imitation alloy) prepared, Ni-Ti shape memory effect depending on the coating and the nature of most of the spray control process.

Lee [7] used plasma spraying to coat $\mathrm{Al} 2 \mathrm{O} 3, \mathrm{Al} 2 \mathrm{O} 3+$ $3 \% \mathrm{TiO} 2, \mathrm{Al} 2 \mathrm{O} 3+13 \% \mathrm{TiO} 2, \mathrm{Al} 2 \mathrm{O} 3+40 \% \mathrm{TiO} 2$ four different ceramic powders on the 6061 aluminum alloy, and then re-fuse by laser to reduce the disadvantages of the porous coating. Cracks exist because of the large differences in thermal conductivity and thermal expansion coefficient between the ceramic coating and the substrate. The generation of cracks can be reduced by using stainless steel as the substrate. Also, raising the preheating temperature can reduce porosity.

Ko and Robertson [8] in order to understand and seek to replace hexavalent chromium surface coating of the carcinogenic process, as aircraft landing gear, HVOF WCCo coatings of abrasion tests conducted at room temp. and $21^{\circ} \mathrm{C}-40^{\circ} \mathrm{C}$, found its good wear resistance.

Bartuli et al [9] in order to force the flow equation simulation WC-Co Nano HVOF spray coating process in the best parameters, explore the combustion flame and particle flow of hot gas chemical and dynamical properties of WC-Co coated nanostructures affected layer by abrasion tests found nanostructure coating having a low coefficient of friction, and having high hardness and high fracture toughness.

Based on the above studies, using the spray method can indeed improve the surface hardness of the substrate, but in the process due to incomplete powder bulk produce large voids in the coating layer or sandwiched impurities, and reduce the binding strength of the coating layer. Flame-sprayed techniques is used in this paper to coat Ni$\mathrm{Cr}-\mathrm{B}-\mathrm{Si}$ powder on low-carbon steel or bearing steel materials of the journal surface. As used herein, manner to grind the thickness of cladding layer sequentially removed, and then use the wear tester to explore material properties of the binding capability, surface hardness, wear and friction within each layer depth. The normal force is applied in addition to the cladding layer by not only using bearing ball but also oil seal pieces, to explore rubber material of oil seal contact journal, Mount Run characteristic between the two., explores the influence of spray material and processing conditions for tribologic characteristics of cladding layer. In experiments to explore the material and processing conditions affect the microstructure and hardness of the cladding layer, and at the same hardness, surface roughness to affect the performance of the mill run.

\section{Specimen production}

The work principle is shown by Figure 1(a), a powder alloy is heated by oxyacetylene flame and blown to be accelerated by gas jet to a high velocity. Flame spray equipment, spray gun, and its various nozzles in bottles for protection can be seen in Figures 1(b) and 1(c). In use, the required oxygen pressure is $4.0 \mathrm{bar}, 0.7 \mathrm{bar}$ acetylene and compressed air 0-6bar. This equipment can coat low-temperature metal powder, self-fluxing powder, ceramic powder, and aluminum, zinc, plastic and other low melting point materials. Spray a round shaft specimen should be held horizontally erected by a controllable speed chuck as shown by the right front of the device to cruise shaft rotating with constant speed and a flame spray gun fixed by fixture as shown on the left rear, lower left corner of the pipeline respectively is connected to a power outside of the picture, the compressed air source and oxygen-acetylene gas source, the mixed powder is packed in the top of the spray gun opening inverted tank.

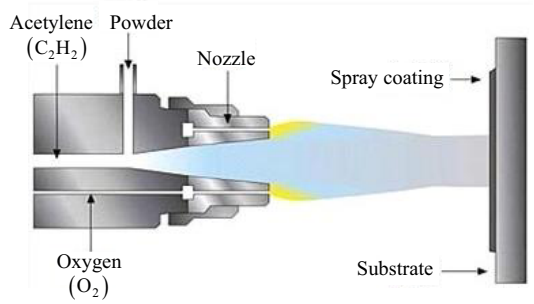

(a) principle

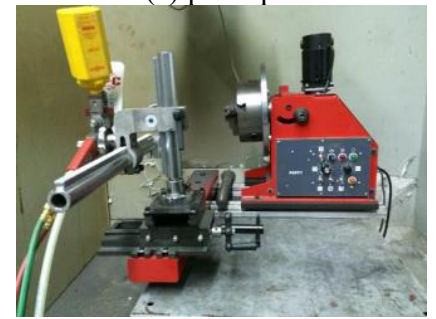

(b) equipment

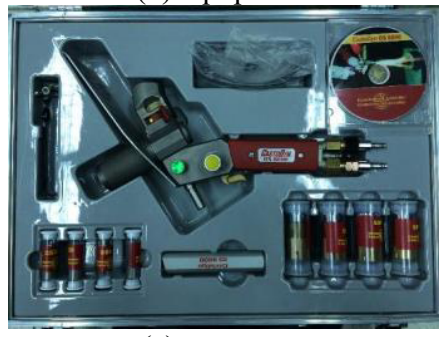

(c) spray gun

Figure 1. Illustrations of flame spray

$\mathrm{Ni}-\mathrm{Cr}-\mathrm{B}-\mathrm{Si}$ alloy powder is a self-fluxing powder, mixed elemental powders need to use mixer devices and ultrasonic vibration machine, stir and put in a beaker, the beaker is placed in the oven by $60{ }^{\circ} \mathrm{C}$ air-dried to 2 hours, and finally these finished powder into standard containers. $\mathrm{Ni} 72.4, \mathrm{Cr} 15 \%$, B 3.25\%, Si $4.5 \%$ with $\mathrm{C}$ and $\mathrm{Fe}$ balance of powder contents are used in this paper. Both substrates are used, which are the AISI52100 bearing steel solid round ring with width $19 \mathrm{~mm}$ and grinded to $68 \mathrm{~mm}$ diameter, and low carbon steel sheet with length $73 \mathrm{~mm}$, width $33 \mathrm{~mm}$ and grinded to $7 \mathrm{~mm}$ thickness. Required specimen fixed using a grinder and surface pre- 
treatment, the purpose of pre-treatment to remove the surface layer fatigue, oil, iron black, rust and other parts, while increasing the surface roughness of the test piece, the spray coating adhered more not falling.

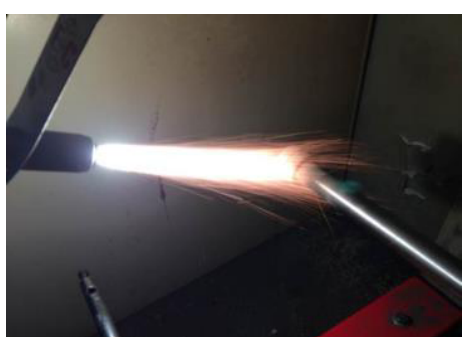

(a) pre-heating and flame-spray

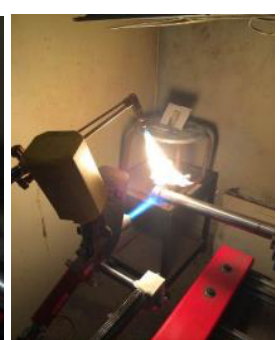

(b)reheat

Figure 2 flame-spray process

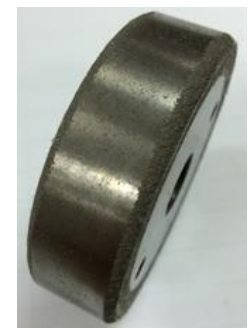

(a) $\mathrm{Ni}-\mathrm{Cr}$ coating

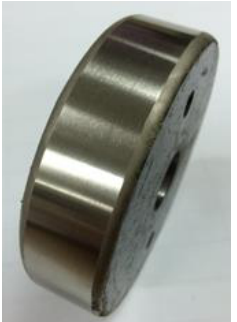

(b) Ni-Cr-B-Si coating
Figure 3 Comparison in finished specimens

Flame spray gun is used to preheat piece in spray coating process as shown in Fig. 2(a), spray guns is maintained a certain distance from the specimen, preheated to the operating temperature (preheating temperature depends on the spray coating material powder), after turning spray under cover switch gun powder spray an even coating to a desired thickness to start to examine the quality and size of the sprayed layer. The reheat process is required for material of sprayed self-fluxing powder after the completion of the above steps, the use of the spray gun to melt the test piece spray layer is heated again. Reheat as seen in Fig 2(b) raises coating material temperature to the melting point to achieve hardening effect by the enhancement of binding force. In this paper, cylindrical specimen diameter $70 \mathrm{~mm}$, spraying speed between 70-180rpm, reheat speed between 30-60rpm, both speeds adopted can be no significant influence for finished quality. After reheat, specimens are required to be cooling in room temperature. If the cooling is too fast, make shrinkage stress in coating layer can be too large to make broken off or shrinkage deformation. At last the specimen surface is finished by grinding. This article uses the flame spray to coating material $\mathrm{Ni}-\mathrm{Cr}$ powder and Ni-Cr-B-Si powder on ring surface of mild steel substrate and the bearing steel AISI52100. Figs. 3(a) and 3(b) show both finished specimens which have been coated and grinding finished by $\mathrm{Ni}-\mathrm{Cr}$ and $\mathrm{Ni}-\mathrm{Cr}-\mathrm{B}-\mathrm{Si}$.

\section{Tribological performance test}

The use of multi-function wear test machine of the ball-on-ring type, a three rotary degree of freedom ball is pressed on the rotating specimen ring with SAE 15W/40 oil (viscous index $\mathrm{VI}=134$, kinematic viscosity is 106.2 $\mathrm{cSt}$ at $40^{\circ} \mathrm{C}$ and $14.06 \mathrm{cSt}$ at $100^{\circ} \mathrm{C}$ ) of wet test to evaluate tribological performance of the flame spray coating specimen. Also, the ball is replace by a seal rubber to simulate the spindle contacted by mechanical seal which is evaluated by is abrasion ability. Applying load $10 \mathrm{~N}, 50 \mathrm{~N}, 100 \mathrm{~N}$ on ball and rotating ring with speed 300rpm, 500rpm, 700rpm in cross wear test, 100 minutes to observe the various hierarchical wear scar spray coating conditions of the trend of increase wear time.

In wear test, the ram of specimen clamp is deformed because of the friction which is measured by strain gauge to determine force which is divided by the applied load and the coefficient of friction can be obtained. While $\mathrm{K}$ type thermocouple including temperature recorder is used to measure temperature rise of oil in the wear test. The record of temperature rise can reflect heat generating and dissipation due to friction and abandon the influence of environmental temperature. The first use basis weight (10kgf) of Rocwell hardness testing applies on specimen and load is added sequentially and kept an appropriate time, and then the load is returned to basis. The use of indentation depth due to load 150kgf applied by diamond cone and steel ball for Rockwell hardness can be determined by $\mathrm{HRC}=100-0.5 \mathrm{~h}$ and $\mathrm{HRB}=130-0.5 \mathrm{H}$, respectively. In general, $\mathrm{HRC}$ is suitable for iron and steel materials, HRB is suitable for measuring relatively soft material of low carbon steel, copper, aluminum etc..

\section{Analysis results of the relationship between abrasion spray coating and ball}

\subsection{Influence of coating thickness, material, and method for surface hardness}

The test piece spray evenly coated $\mathrm{Ni}-\mathrm{Al}$ alloy powder which rose a thickness of $2 \mathrm{~mm}$, the specimen to be done to complete spray coating each layer hardness measurement, this experiment is $0.3 \mathrm{~mm}$ floor, ground to the desired thickness using a grinder that is using the Rockwell hardness machine hardness measurement, measurement continues to complete the above steps until the spray coating is exhausted, hardness and thickness affect the relationship shown in Figure 4(a). The results from that, due to the measurement of the hardness of Rockwell hardness, it is the ultimate measure of the depth of the indentation. If the thickness is greater than the amount of the indentation depth measured values are similar, the results of this experiment thus decided to give the antiwear material reserve amount of $1 \mathrm{~mm}$ thickness of the wear test as a benchmark. Since the Ni-Al alloy as a base to use just simply increase the adhesion of spray coating and the test piece. Its hardness is too soft (HRB78) so we doesn't use it. Hardness of Ni-Cr alloy although already higher than the mild steel sheet, but still less than the surface hardness of the steel to improve the bearing requirements. The results can be known from Fig. 4(b).

$\mathrm{Ni}-\mathrm{Cr}$ alloy by spray coating contained after many pores so that adhesion and hardness limited rise; boron alloy powder within the $\mathrm{Ni}-\mathrm{Cr}$, elemental silicon powder and increase financial Run procedures so that the specimen surface hardness increased dramatically. The alloy microstructure of $\mathrm{Ni}-\mathrm{Cr}$ and $\mathrm{Ni}-\mathrm{Cr}-\mathrm{B}-\mathrm{Si}$ sprayed coating are shown in Figs. 5(a) and 5(b), respectively. This photo reveals that $\mathrm{Ni}-\mathrm{Cr}$ alloy in the distribution of large pores and spray cover loosely organized, uneven, 
this is because they do not entirely caused by the accumulation of the metal spray coating process between the particles. Reversely, Ni-Cr-B-Si alloy melt due to reheat through the process gas overflow, so that the surface of dense, thereby improving the quality test strip.

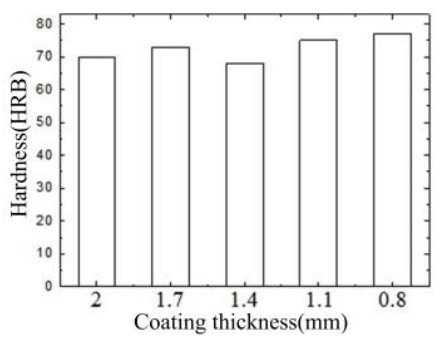

(a) Variations of HRB in coating layer

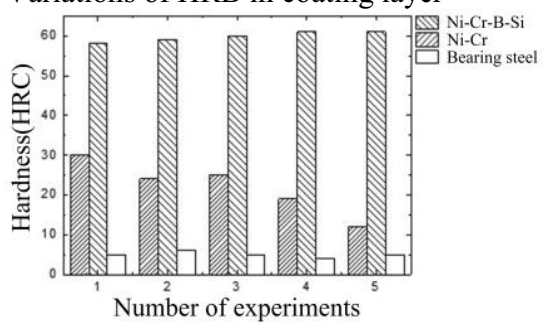

(b) Comparison of three materials

Figure 4 Hardness measurement results

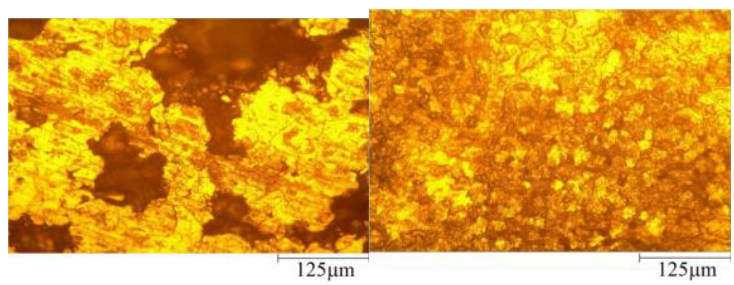

(a)Ni-Cr alloy coating

(b)Ni-Cr-B-Si alloy coating

Figure 5 Microstructure photos of flame-spray coating

\subsection{Wear between the ball and spray coating surface}

For testing time 230 minutes with rotating speed 500 rpm and applied load, adhesive wear in contact is transferred from a softer material friction surface to another surface of the rubbing harder, causing loss of material, the main features of the traces of friction and wear of the surface of the elongated strip and tear marks on hard surfaces can stick more than the material as shown in Fig. 6. The Fig. 6(a) for coating Ni-Cr alloy black stripes on the surface of adhesive wear are shown, Figs. 6(b) and 6(c) to the original bearing steel panels and surface spray coating Ni-Cr-B-Si alloy specimen from the figure apparent steel panels bearing wear scar darker, which represents more serious wear and tear, its hardness and alloy gap Ni-Cr-B-Si small, so that the impact of the coefficient of friction material wear is important.

After the wear test was observed using an optical microscope can be seen in Fig. 7, wherein the Ni-Cr alloy due to soft texture and uneven surface, so the hard texture of the surface of the ball will be less damage and wear scar also relatively obvious, but the specimen is generated serious scratches. Ni-Cr-B-Si alloy hardness is similar to bearing steel, but its grind marks and scratches are more shallow than bearing steel. Because Ni-Cr-B-Si alloy steel bearing surface texture of good surface roughness and friction between the ball relatively peaceful, so is better than the original mill-run feature of bearing steel.

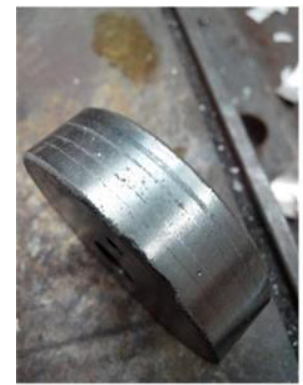

(A) $\mathrm{Ni}-\mathrm{Cr}$

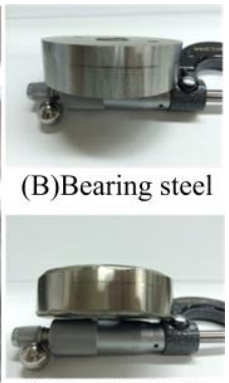

(C)Ni-Cr-B-Si
Figure 6 Surface adhesion on after wear test

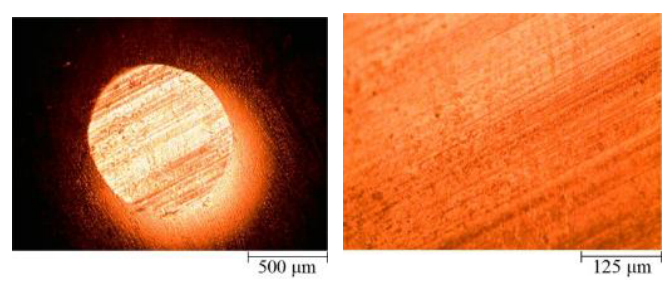

(a) $\mathrm{Ni}-\mathrm{Cr}-\mathrm{B}-\mathrm{Si}$

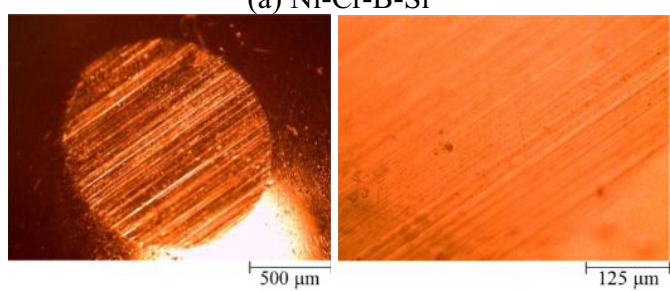

(b) $\mathrm{Ni}-\mathrm{Cr}$

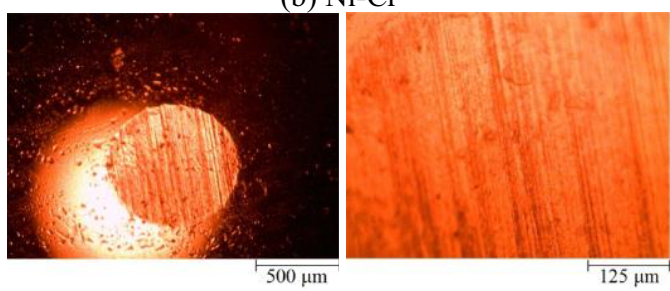

(c) Bearing steel

Figure 7 Adhesive observation after wear test (left $\times 200$ magnification and right $\times 50$ magnification)

\subsection{Friction and surface roughness analyses for flame spray coating}

Fig. 8 is a relationship between the coefficient of friction of the test piece and the ball friction reflects the energy loss caused by friction size, while reducing energy consumption in tribology research and to increase the hardness and wear resistance of the sprayed coating is just as important. Friction coefficient measurement process due to the test pieces roundness, so the test strip will produce a slight bounce up and down while rotating the final result data plotted against jitter phenomenon (friction data acquisition: $1 \mathrm{sec} /$ time); $\mathrm{Ni}-\mathrm{Cr}$ alloy is sometimes the reason for low friction coefficient and low surface hardness. The surface layer is scratched caused by the contact area of the grinding ball becomes smaller, resulting in a value near the strain gauge measured becomes small. For Ni-Cr-B-Si alloy compared with the bearing steel, the friction coefficient of Ni-Cr-B-Si alloy is low so the surface of Ni-Cr-B-Si alloy easier to get 
smooth (bright) surface using grinding machine, thereby increasing mill-run nature of the material, spray coating material to reduce surface wear, can be learned from this experiment test, the greater the friction that is greater the abrasion wear test piece, relative scratches will be more obviously (deep).

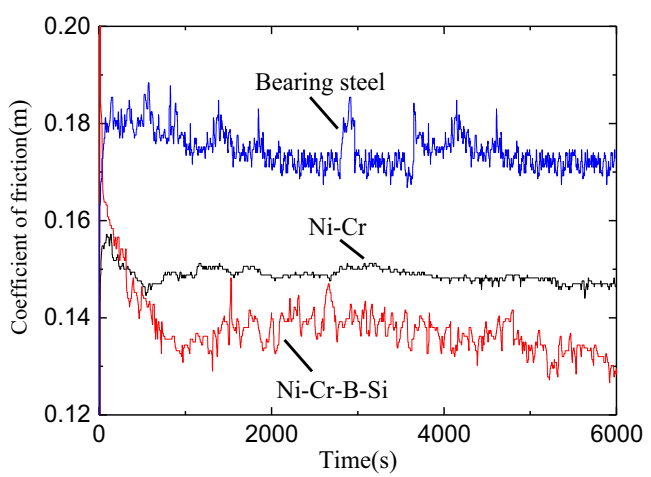

Figure 8 The changes of friction force in wear test

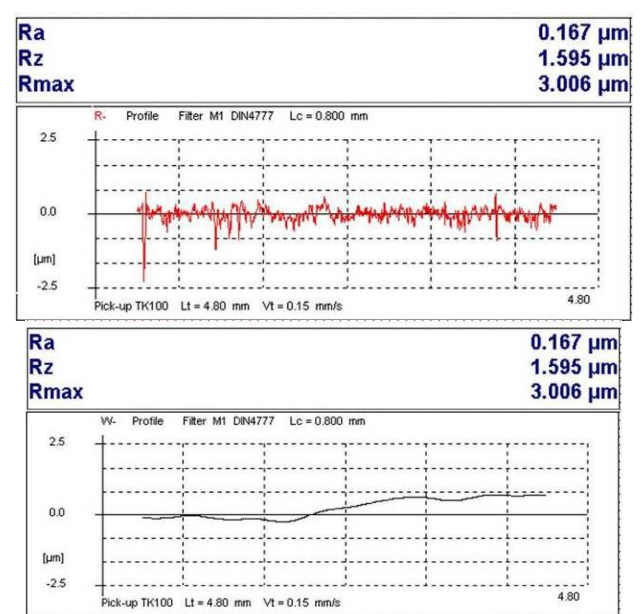

(a) $\mathrm{Ni}-\mathrm{Cr}-\mathrm{B}-\mathrm{Si}$

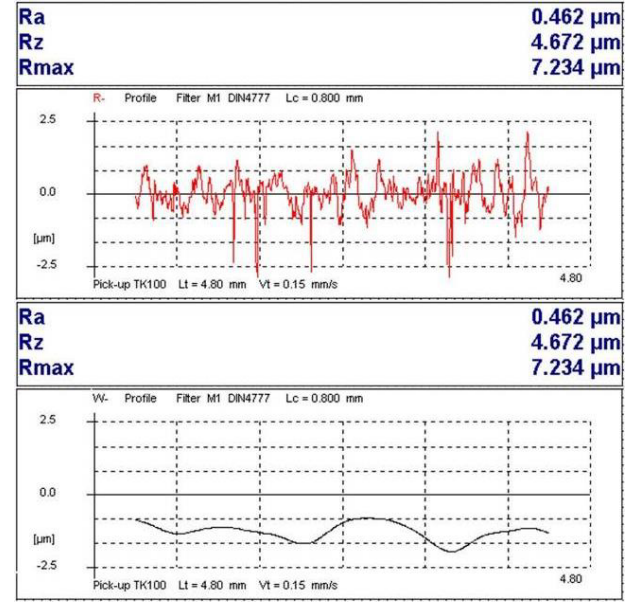

(b) Ni-Cr

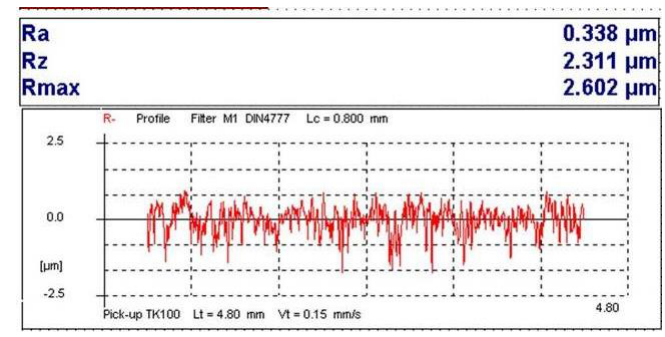

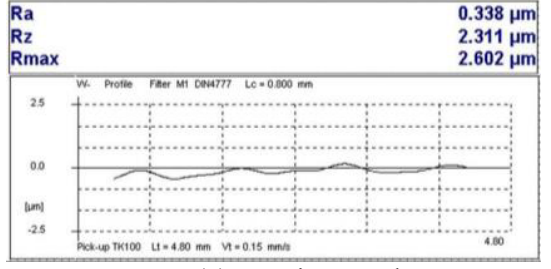

(c) Bearing steel

Figure 9 Surface roughness of flame-spray coating (upper are $\mathrm{R}$ contours and lower are $\mathrm{W}$ contours)

Fig. 9 is a result after roughness measuring machine, in which a test piece are two graphs show, respectively, the roughness parameters ( $\mathrm{R}$ and collectively outline) and corrugation parameters ( $\mathrm{W}$ and collectively outline). $\mathrm{Ni}$ $\mathrm{Cr}$ alloy surface most rough, because the impurities entrained with the pores in the spray coating process, resulting in hardness and binding capacity are greatly reduced due to the abrasion test after surface pit scars, scratches, Ni-Cr-B-Si W R value map and graph alloys are bearing steel than good to come, it also proves that the gap between the small hardness, the denser the material surface roughness, the better, the better the wear resistance, the figure has continued to $\mathrm{W}$ Figure raise or lower the platform to the test strip or slightly tilted due to contour beyond all who desire to maintain a clear illustration of the same magnification and the commitment now, it's too rough segments would exceed the display range.

\section{Wear of flame spray coating}

A seal as shown in Fig. 10 is constructed by rubber body, metal ring, and Garter spring which presses the seal lip to forced contact journal. This paper uses common NBR(Acrylonitrile butadiene rubber) to apply load on cutting into bulk to be fixed on tester fixture and sandwiched abrasion test machine table, so that the test piece in contact with the seal, this test method for testing purposes only seal material and spray coating and wear characteristics of the relationship between the steel bearing comparison. Fig. 11 is a seal abrasion wear condition after the experiment and to wear the seal bearing steel has been noticeable scratches and cracks (black part), the seal of the mill and Ni-Cr-B-Si alloy it is only in case of the emergence of the rubber will produce heat after swelling phenomenon.

Figure 12 (left) and bearing steel and Ni-Cr-B-Si alloy seal comparison chart for friction wear trends, the data jitter test piece is part roundness caused, Ni-Cr-B-Si alloy Run of the mill more primitive characteristics of good bearing steel, bearing steel specimens because the surface roughness is poor, so the friction generated is larger, the seal is damaged more serious. This part of the test results represent, among spray coating materials and seal materials are not mutually exclusive phenomenon will occur, and extent of the damage and the test piece surface friction seals have a proportional relationship. Figure 12 (right) and bearing steel and Ni-Cr-B-Si alloy and seal against the grinding lubricant temperature trend comparison chart, the figure shows, spray coating test piece Ni-Cr-B-Si alloy of the wear when the oil temperature is high and the test temperature a little faster 
due to the coating layer containing the constituent elements of B (boron), boron ceramic material thermal conductivity (27.4) than the bearing steel test piece (46.6) is poor, so in experiments $\mathrm{Ni}-\mathrm{Cr}-\mathrm{B}-\mathrm{Si}$ alloy specimen can not be introduced into the lubricating oil due to the heat generated by the friction of the test sheet, resulting in a lower Ni-Cr-B-Si alloy specimen temperature but higher oil; opposite bearing steel panels due to better thermal conductivity, heat easily import test lubricant film, resulting in high temperature bearing steel panels, the lower the oil temperature results.

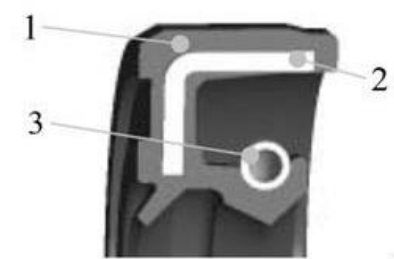

Figure 10 Oil seal structure(TC type)
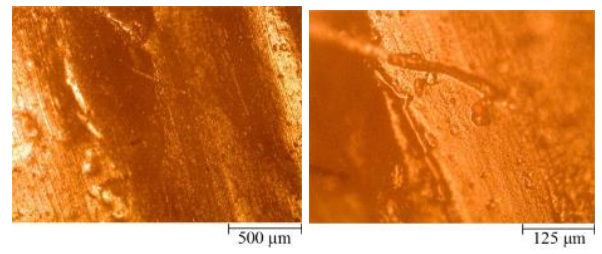

(a) Bearing steel

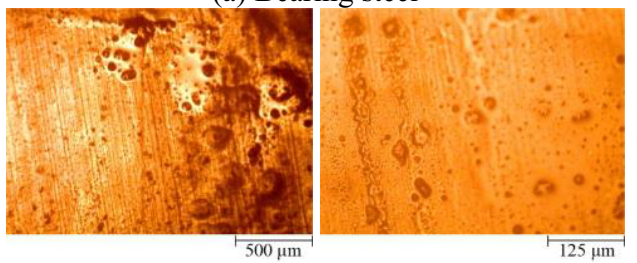

(b) Ni-Cr-B-Si

Figure 11 The extent of the test strip to seal wear loss of test conditions: seal material NBR, oil products $80 \mathrm{~W} / 90$, the rotational speed $300 \mathrm{rpm}$, load $250 \mathrm{~N}$, wear time 230 minutes (left $\times 50$ magnification and rignt $\times 200$ magnification)
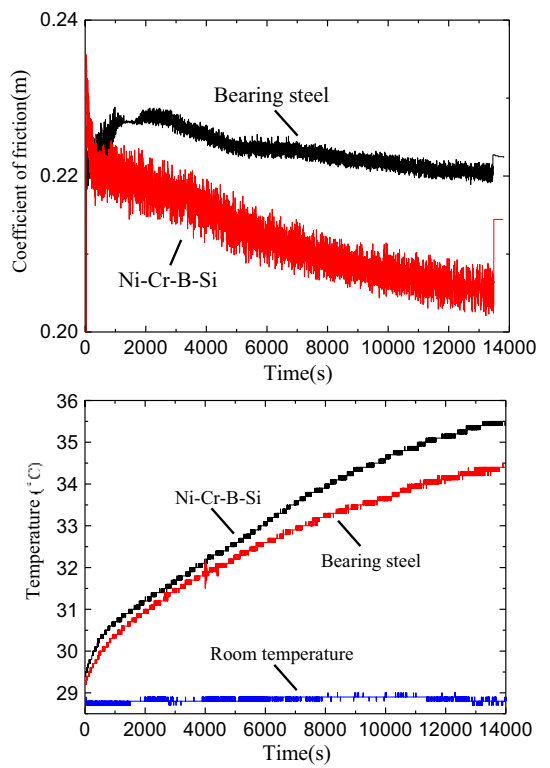

Figure 12 Top is the friction relationship between the specimen and oil seals, and bottom is the relationship oil temperature changed. Abrasion test conditions: Seal material NBR, oil products $80 \mathrm{~W} / 90$, the rotational speed $300 \mathrm{rpm}$, load $250 \mathrm{~N}$, wear time 230 minutes.

\section{Conclusion}

The flame spray coating can improve tribological performances for both spindle journal and seal, this study has drawn the following points: (1) The use of Ni-Cr-BSi alloy powder spray coated on mild steel and reheated coating to melt, the bonding strength thus can be enhanced, to increase substrate hardness, to raise wear resistance and to reduce friction coefficient because spray coating hard particles $\mathrm{Cr}$ and protection particles $\mathrm{Ni}$ are distributed uniformly. (2) For the same hardness, the lower surface roughness is the better ability of resistance to wear and surface scratches is. (3) Powder incomplete due to the accumulation of the coating can be influenced by the spray distance and the gas flow rates, which induces large and small pores, thereby affecting the spray coating bond strength and wear ability, the more the number of stomata spray coating mechanical properties more difference (4) spray coating Ni-Cr-B-Si alloy in the specimen, its thermal conductivity is poor, due to friction caused by rising oil temperature has little effect on the test piece (but cannot because of the heat and the oil temperature rises ), is less likely to make the inter-friction surface temperature continues to rise and damage the oil seal surface structure.

\section{Acknowledgments}

The authors deeply indebted to the Minister of Science and Technology, R.O.C., under the contracts NSC1022221-E-033-021 for their financial supports.

\section{References}

1. Y. Wang, W. Chen, L. Wang, Micro-indentation and Erosion Properties of Thermal Sprayed NiAl IntermetallicBased Alloy Coatings, Wear 254, 350-355 (2003).

2. W. Simm, S. Freti, Abrasive wear of multiphase materials, Wear 129, 105-121 (1989).

3. J. Fohl, T. Weissenberg, J. Wiedemeyer, General aspects for tribological application of hard particle coatings, Wear 130, 257-288 (1989).

4. Kwang-Lung Lin, Ming-Yeong Hwang, Cheng-Dau Wu, The deposition and wear properties of cathodic arc plasma deposition TiAlN deposits, Materials Chemistry and Physics 46, 7-83 (1996).

5. Y. L. Qiao, B. S. Xu, S. N. Ma, X. B. Liang, J. C. Chi, Tribological Properties and Mechanism of Fe-Cr-Ni Coating, Jixie Gongcheng Xuebao/Chinese Journal of Mechanical Engineering 38, (2002).

6. H. Hiraga, T. Inoue, H. Shimura, A. Matsunawa, Cavitation Erosion Mechanism of NiTi Coatings Made by Laser Plasma Hybrid Spraying, Wear 231, 272-278 (1999).

7. Ying-Da Li, A Study of Al2O3/TiO2 Coatings by PlasmaSprayed for High Dielectric Application, Master's thesis, NCTU (2001).

8. P. L. Ko, M. F. Robertson, Wear Characteristics of Electrolytic Hard Chrome and Thermal Sprayed WC$10 \mathrm{Co}-4 \mathrm{Cr}$ Coatings Sliding against Al-Ni-Bronze in Air at $21^{\circ} \mathrm{C}$ and at $-40^{\circ} \mathrm{C}$, Wear 252, 880-893 (2002).

9. L. Valentinelli, T. Valente, F. Casadei, L. Fedrizzi, Mechanical and Tribocorrosion Properties of HVOF Sprayed WC-Co Coatings, Corrosion Engineering Science and Technology 39, 301-307 (2004). 